\title{
THE ROLE OF GROUP EDUCATIONAL PROGRAMS IN MODIFICATION OF THE CARDIOVASCULAR RISK MAIN FACTORS
}

\author{
Anna Isayeva \\ Department of Complex reduce of the risk of chronic non-infectious \\ The Government Institution "National Institute of Therapy named by L. T. Malaya of National \\ Ukrainian Academy of Medical Science" \\ 2 A Lubovi Maloy ave., Kharkiv, Ukraine, 61039 \\ anna_isayeva_74@yahoo.co.uk \\ Larysa Rieznik \\ Department of Complex reduce of the risk of chronic non-infectious diseases \\ The Government Institution "National Institute of Therapy named by L.T. Malaya of National \\ Ukrainian Academy of Medical Science" \\ 2 A Lubovi Maloy ave., Kharkiv, Ukraine, 61039 \\ larisareznik@ukr.net \\ Maryna Vovchenko \\ Department of Complex reduce of the risk of chronic non-infectious diseases \\ The Government Institution "National Institute of Therapy named by L.T. Malaya of National \\ Ukrainian Academy of Medical Science" \\ 2 A Lubovi Maloy ave., Kharkiv, Ukraine, 61039 \\ calanta@rambler.ru \\ Olena Buriakovska \\ Department of Complex reduce of the risk of chronic non-infectious diseases \\ The Goverment Institution "National Institute of Therapy named by L.T. Malaya of National \\ Ukranian Academy of Medical Science" \\ 2A Lubovi Maloy ave., Kharkiv, Ukraine, 61039 \\ alena.tbtch@gmail.com
}

\begin{abstract}
Aim - to study the influence of Healthy Schools "Healthy Lifestyle Basis" education on modifying of cardiovascular risk main factors.

Materials and methods. 57 patients with cardiovascular diseases were examined. General clinical examination, anthropometric examinations (body weight, height, body mass index, and body composition), blood pressure measurement, and cholesterol determination, as well as its fractions in blood, were carried out before and after training course. The educational cycle included 9 lessons.

Results. It was found that Healthy Schools education contributes to better both systolic and diastolic blood pressure monitoring. Thus, initially target blood pressure levels $(<140 / 90 \mathrm{mmHg}$ for patients without diabetes mellitus and $<140 / 85 \mathrm{mmHg}$ in case of diabetes) were observed in $49 \%$ of patients, at the end of the training cycle - in $67 \%$. At the same time, the patients' anthropometric parameters (BMI, fat and muscle tissue content, visceral fat) as well as cholesterol and its atherogenic serum fractions, did not change significantly. The patients' education did not affect motivation level for their lifestyle improvement. So the number of patients consuming less than 5 grams of table salt per day and over 400 grams of vegetables and fruit did not change significantly. The level of physical activity between the examined patients did not change.

Conclusion. The training course "Healthy Schools: Healthy Lifestyle Basis" contributes to improvement of blood pressure level monitoring, but does not significantly affect behavioral risk factors and does not lead to improvement of lipid metabolism monitoring in patients with cardiovascular disease. It is necessary to search for new more effective preventive care models for patients with high cardiovascular risk.
\end{abstract}

Keywords: cardiovascular prophylaxis, group educational programs, group preventive counseling. 


\section{Introduction}

Measures for active cardiovascular prevention are the most important condition for morbidity and mortality reducing [1]. In most developed countries, specialized prevention programs for people with high cardiovascular risk and patients with cardiovascular diseases, based on learning of medical knowledge basics, practical development of measuring blood pressure techniques, development of individual diet plan, increase physical activity, etc. , have been introduced into public health practice [2]. At the same time it was determined that the patients education aimed at explaining the role of a particular risk factor in cardiovascular diseases development or their complications improves the patients adherence to healthy lifestyles principles [3, 4]. The efficiency and economic feasibility of educational programs are confirmed by numerous studies [5, 6]. In 2016, a program of cardio rehabilitation for countries with low socioeconomic level, including Ukraine, was proposed [7].

In the context of limited resources, efficiency evaluation of the presented preventive care model, such as group educational cycles - Schools of Patients - is of a particular interest [8]. It is shown that education in the Schools helps to effectively correct the main behavioral risk factors, improves emotional state and quality of life of patients, and increases their adherence to long-term drug therapy. The development of an effective training program for patients aimed at monitoring of cardiovascular risk main factors would reduce the financial burden on the existing health care system.

\section{Aim of research}

To estimate the influence of Healthy Schools "Healthy Lifestyle Basis" education on modifying of cardiovascular risk main factors in patients with high and very high cardiovascular risk.

\section{Materials and methods}

The study was carried out on the basis of Department of chronic non-infectious diseases comprehensive risk reduction of the State Institution "National Institute of Therapy named after L. T. Malaya of NAMS of Ukraine”, Kharkiv, during 2016-2018.

\section{Study Limit:}

57 patients with cardiovascular diseases were examined. The mean age of the patients was $(63.3 \pm 2.2)$ years. The patients' descriptions, depending on the nosological forms are presented in Table 1.

Table 1

The patients' descriptions, depending on the nosological forms

\begin{tabular}{lcc}
\hline \multicolumn{2}{c}{ Nosological forms } & Number of patients (n (\%)) \\
\hline \multirow{2}{*}{ Hypertensive heart disease } & Stage II & $32(56 \%)$ \\
& Stage III & $25(44 \%)$ \\
CHD & II function. cl. & $40(70 \%)$ \\
& III function. cl. & $7(12 \%)$ \\
& Myocardial infarction in anamnesis & $21(37 \%)$ \\
Revart failure II, III function. cl. (NYHA) & $8(14 \%)$ \\
Diabetes mellitus type 2 & $50(88 \%)$
\end{tabular}

The lectures cycle was developed for patients with high and very high cardiovascular risk; it includes 9 lessons, each lesson included the lecture material, as well as practical work with the patient, dietician and exercise therapist. The practical part included detailed analysis of the individual nutrition features and the necessary physical exercises, the individual patient's diary data 
were estimated, and a practical task for the next month was given. The patients were trained to calculate their individual caloric needs, and to estimate food products composition. As a part of these lessons, information concerning the most common chronic non-infectious diseases: coronary heart disease, hypertensive heart disease, diabetes mellitus, musculoskeletal disorders, thyroid gland disorders, and the central nervous system age-associated lesions was given to the patients. A particular attention was paid to highlight of the role of known risk factors in the development and progression of the mentioned diseases, the importance of these risk factors modification, as well as the most effective methods for their correction. Also dietary recommendations and instructions for physical activity were analyzed in detail. At the beginning of the cycle, the patient receives methodical materials, and individual diary. The use of the diary allows the patient to estimate individual risk factors (body mass index, fat and muscle tissues content, visceral fat, blood glucose and lipid levels) with a doctor.

All patients were examined before and after the the educational program cycle. The questionnaire assessed behavioral risk factors: the amount of table salt per day (less or more than 5 grams per day), fruit and vegetables (less or more than 400 grams), smoking (in the past and now), and alcohol consumption. Physical activity of the patients was calculated by the number of steps within 24 hours. General clinical examination, blood pressure measurement (BP), anthropometric examinations (body weight, height, body mass index, fat and muscle tissue, and visceral fat), determination of cholesterol and its fractions was carried out. The amount of fat and muscle tissue, and visceral fat was determined by bioelectrical impedance method using Omron Body Composition Monitor BF511. Muscle strength was determined using electronic car dynamometer Camry EH 101.

The achievement of target blood pressure levels (BP) was assessed in accordance with the European Society of Cardiology (2013) recommendations [9]. The target office blood pressure level was $<140 / 90 \mathrm{mmHg}$ and $140 / 85 \mathrm{mmHg}$ in case of diabetes. It was considered that the patient achieves the target blood pressure level, if in case of a double measurement with an interval of 1 month the office BP did not exceed the above levels.

Achievement of lipid metabolism target levels was assessed in accordance with the European Society of Cardiology recommendations (2016). Target level of low-density lipoprotein cholesterol (LDL-C) was $<2.6 \mathrm{mmol} / 1$ or its decrease at least for $50 \%$, if the initial level was $2.6-5.1 \mathrm{mmol} / 1$, for patients with high cardiovascular risk; and $<1.8 \mathrm{mmol} / 1$ or at least $50 \%$ decrease if the initial level was $2.6-5.1 \mathrm{mmol} / \mathrm{L}$, for patients with very high cardiovascular risk [10].

The lipid blood spectrum was determined by the enzymatic method using "Humalyzer 2000” biochemical analyzer, №18300-5397.

The study protocol was approved by the local ethical commission of the State Institution "National Institute of Therapy named after L. T. Malaya of NAMS of Ukraine". The study was carried out in accordance with the principles of the Helsinki Declaration. All patients signed an agreement to participate in the study.

The statistical data processing was carried out using the statistical software package “SPSS 21” (IBM), Microsoft Office Excel-2003.

\section{Results}

The survey results analysis shows that the majority of patients $-51(89.5 \%)-$ did not smoke in the past and do not smoke now; 4 smoked in the past, and 2 still smoke at the moment of the study. The questionnaire data show that 2 patients $(3.5 \%)$ used alcohol in moderate amounts (1-2 servings per day) in the past, the other - very rarely or in such small amounts that it can be neglected. Despite Health Schools training, 1 person continues smoking.

There were no significant changes in other behavioral risk factors. For example, 13 (22.8 \%) patients actively ate vegetables and fruit before the beginning of education, and 14 of them $(24.5 \%$, $\mathrm{p}>0.05)$ after the training finishing, as well as the number of patients consuming less than $5 \mathrm{~g}$ of table salt per day - $(28.1 \%$ before and $22.8 \%$ after, $\mathrm{p}>0.05)$. Also, the patients' physical activity was not significantly increased, as it was determined by the number of steps during the day -2108 $[524 \div 5099]$ steps initially and $1988[440 \div 41289]$ steps after the education, $\mathrm{p}>0.05$. 
After the educational programs, the main anthropometric features of the patients, as well as the indexes characterizing body composition, did not change significantly (Table 2).

Table 2

The patients' anthropometric features before and after training in Healthy Schools

\begin{tabular}{|c|c|c|c|}
\hline Index & $\begin{array}{l}\text { Before training }(n=57) \\
\text { Me }[25 \div 75 \%]\end{array}$ & $\begin{array}{c}\begin{array}{c}\text { After training } \\
(n=57)\end{array} \\
\text { Me }[25 \div 75 \%]\end{array}$ & $\mathbf{P}$ \\
\hline Body weight, kg & $86.1[75.6 \div 100.7]$ & $87.9[76.6 \div 97.7]$ & 0.7987 \\
\hline Body mass index, $\mathrm{kg} / \mathrm{m}^{2}$ & $31.6[27.6 \div 38.2]$ & $34.4[28.9 \div 37.6]$ & 0.4322 \\
\hline Fat tissue, $\%$ & $42.0[341 \div 50.0]$ & $43.9[35.3 \div 49.1]$ & 0.6953 \\
\hline Visceral fat, $\%$ & $12.0[10.0 \div 14.0]$ & $12.0[10.0 \div 15.0]$ & 0.6223 \\
\hline Muscle tissue, \% & $25.5[22.3 \div 28.8]$ & $24.6[22.5 \div 28.4]$ & 0.7332 \\
\hline
\end{tabular}

Muscle contraction strength also did not change significantly $-27.9[23.2 \div 40.2] \mathrm{kg}$ before the beginning and $27.4[21.9 \div 32.4] \mathrm{kg}$ after the end of the educational cycle, $\mathrm{p}=0.0925$.

Initially, target blood pressure levels were noted in $49 \%$ of patients. Lessons in Health Schools contribute to the improvement of this indicator - by the end of the educational cycle, target BP levels were observed in $67 \%$ of patients (Table 3).

Table 3

Blood pressure levels in the patients before and after Healthy Schools education

\begin{tabular}{cccc}
\hline Index & Before training $(\mathbf{n}=\mathbf{5 7}) \mathbf{M} \pm \mathbf{m}$ & After training $(\mathbf{n}=\mathbf{5 7}) \mathbf{M} \pm \mathbf{m}$ & $\mathbf{P}$ \\
\hline SBP, $\mathrm{mmHg}$ & $141.8 \pm 16.2$ & $123.4 \pm 9.3$ & $\mathrm{p}=0.001$ \\
DBP, $\mathrm{mmHg}$ & $88.1 \pm 9.8$ & $76.0 \pm 8.8$ & $\mathrm{p}=0.001$
\end{tabular}

Before the training start, the total cholesterol target levels (TC) and low-density lipoprotein cholesterol (LDL cholesterol) were observed in $49 \%$ of patients, in 9 months of training - in $35 \%$ of patients (Table 4).

Table 4

Lipid metabolism indexes before and after Healthy Schools education

\begin{tabular}{cccc}
\hline Index & $\begin{array}{c}\text { Before training }(\mathbf{n}=\mathbf{5 7}) \\
\text { Me }[\mathbf{2 5} \div \mathbf{7 5} \% \mathbf{\%}]\end{array}$ & $\begin{array}{c}\text { After training }(\mathbf{n}=\mathbf{5 7}) \\
\text { Me }[\mathbf{2 5} \div \mathbf{7 5} \% \mathbf{~ \%}\end{array}$ & $\mathbf{P}$ \\
\hline Total cholesterol, mmol/1 & $5.17[4.25 \div 6.18]$ & $5.82[4.59 \div 6.42]$ & $\mathrm{p}=0.1505$ \\
Cholesterol HDL, $\mathrm{mmol} / 1$ & $1.40[1.16 \div 1.63]$ & $1.34[1.07 \div 1.64]$ & $\mathrm{p}=0.0769$ \\
Triglycerides, $\mathrm{mmol} / 1$ & $1.34[1.14 \div 1.92]$ & $1.52[1.22 \div 2.44]$ & $\mathrm{p}=0.4050$ \\
Cholesterol LDL, $\mathrm{mmol} / 1$ & $2.69[1.95 \div 3.89]$ & $2.78[2.38 \div 3.56]$ & $\mathrm{p}=0.594$
\end{tabular}

\section{Discussion}

A number of different studies point to the efficiency of group training programs devoted to improvement of blood pressure monitoring. Thus, it was shown that the number of patients with improved target blood pressure levels (for $14.3 \%$ ) among the ones attending Healthy Schools has increased. According to Shemetova G.N. et al. data, Healthy Schools education allowed to increase the proportion of patients with a target blood pressure level from $32 \%$ to $42 \%$ [12]. Results of the 
study with 239 patients having hypertensive heart disease, indicate that education at the Healthy Schools improves blood pressure monitoring (initially the number of people with a target blood pressure level was $12.6 \%$, after the end of the training cycle $-50.6 \%, \mathrm{p}<0.05)$. Thus, the number of smokers decreased from $(52.9 \pm 3.2) \%$ to $(37.0 \pm 3.1) \%(p<0.05)$, the number of obese patients - from $(38.2 \pm 3.2) \%$ to $(22.7 \pm 2.7) \%(\mathrm{p}<0.05)$, patients with hypercholesterolemia from $(58.4 \pm 3.2) \%$ to $(41,2 \pm 3.2) \%(\mathrm{p}<0.05)$, patients with hypodynamia - from $(71.4 \pm 2.9) \%$ to $(42.4 \pm 3.2) \%(\mathrm{p}<0.05)[13]$.

According to Kontsevaya, A.V. and co-authors (2011) data, among the CHD patients, who attended Healthy School in addition to their standard therapy, the total cholesterol level decreased by $23.9 \%$; and in the group of patients who had only standard therapy - by $14.3 \%$. Also among the patients educated in Healthy School, target BP levels were $42.5 \%$, and in the standard therapy group $-6.7 \%$.

In the European Recommendations concerning cardiovascular diseases prevention (2016), advantages of individual forms of patient education have shown. In this case, a key role in preventive counselling is assigned to general practitioners. There is a data showing that both nurses and general practitioners can be equally effective in providing individual counselling to correct major cardiovascular risk factors $[15,16]$.

Recently, there is no developed optimal model of preventative care [17]. Its structure, type and duration should be adapted to individual countries, regarding their national standards, legislation, economic opportunities and cultural features. The most efficiency was shown by comprehensive programs, which include such mandatory components like dosed physical activity, risk factors correction, education and psychological support [18, 19]. Also, predictive factor is the intervention duration. Thus, the GOSPEL study results (3.441 participants with recent myocardial infarction) indicate that long (up to 3 years) training programs contribute to improving control of behavioural risk factors (physical activity, diet, body weight control, stress level), and also contribute to drug therapy adherence increase [20].

Development and widespread implementation of specialized prevention programs should be health care priority in countries with a high risk of cardiovascular mortality, including Ukraine. However, the data concerning description of such programs have not been found in the available national literature.

\section{Conclusion}

1. Educational cycle "Healthy Schools: Healthy Lifestyle Basis contributes to BP monitoring improvement.

2. Training in the Healthy Schools does not lead to behavioral risk factors modification.

3. Patients who graduated from the Healthy Schools training did not show lipid metabolism indexes improvement.

4. It is necessary to search for new more effective preventive care models for patients with high cardiovascular risk.

\section{References}

[1] Piepoli, M. F., Hoes, A. W., Agewall, S., Albus, C., Brotons, C., Catapano, A. L. et. al. (2016). 2016 European Guidelines on cardiovascular disease prevention in clinical practice. Atherosclerosis, 252, 207-274. doi: http://doi.org/10.1016/j.atherosclerosis.2016.05.037

[2] Bjarnason-Wehrens, B., McGee, H., Zwisler, A.-D., Piepoli, M. F., Benzer, W., Schmid, J.-P. et. al. (2010). Cardiac rehabilitation in Europe: results from the European Cardiac Rehabilitation Inventory Survey. European Journal of Cardiovascular Prevention \& Rehabilitation, 17 (4), 410-418. doi: http:// doi.org/10.1097/hjr.0b013e328334f42d

[3] Omboni, S., Caserini, M. (2018). Effectiveness of pharmacist's intervention in the management of cardiovascular diseases. Open Heart, 5 (1), e000687. doi: http://doi.org/10.1136/openhrt-2017-000687

[4] Vijn, T. W., Fluit, C. R. M. G., Kremer, J. A. M., Beune, T., Faber, M. J., Wollersheim, H. (2017). Involving Medical Students in Providing Patient Education for Real Patients: A Scoping Review. Journal of General Internal Medicine, 32 (9), 1031-1043. doi: http://doi.org/10.1007/s11606-017-4065-3 
[5] Zwisler, A.-D., Bjarnason-Wehrens, B., McGee, H., Piepoli, M. F., Benzer, W. et. al. (2011). Can level of education, accreditation and use of databases in cardiac rehabilitation be improved? Results from the European Cardiac Rehabilitation Inventory Survey. European Journal of Preventive Cardiology, 19 (2), 143-150. doi: http://doi.org/10.1177/1741826711398847

[6] Benzer, W., Rauch, B., Schmid, J.-P., Zwisler, A. D., Dendale, P., Davos, C. H. et. al. (2017). Exercise-based cardiac rehabilitation in twelve European countries results of the European cardiac rehabilitation registry. International Journal of Cardiology, 228, 58-67. doi: http://doi.org/10.1016/j.ijcard.2016.11.059

[7] Grace, S. L., Turk-Adawi, K. I., Contractor, A., Atrey, A., Campbell, N., Derman, W. et. al. (2016). Cardiac rehabilitation delivery model for low-resource settings. Heart, 102 (18), 1449-1455. doi: http:// doi.org/10.1136/heartjnl-2015-309209

[8] Cardiovascular prevention 2017. National Guidelines (2017). Moscow: Russian Society of Cardilogy, National Society for Cardiovascular Prevention and Rehabilitation, Russian Society for the Prevention of Noncommunicable Diseases, 288.

[9] Mancia, G., Fagard, R., Narkiewicz, K., Redón, J., Zanchetti, A., Böhm, M. et. al. (2013). 2013 ESH/ESC Guidelines for the management of arterial hypertension. Journal of Hypertension, 31 (7), 12811357. doi: http://doi.org/10.1097/01.hjh.0000431740.32696.cc

[10] Catapano, A. L., Graham, I., De Backer, G., Wiklund, O., Chapman, M. J., Drexel, H. et. al. (2016). 2016 ESC/EAS Guidelines for the Management of Dyslipidaemias. European Heart Journal, 37 (39), 2999-3058. doi: http://doi.org/10.1093/eurheartj/ehw272

[11] Karpova, I. P., Shilnikova, N. F. (2011). Estimation of the effectiveness of the activity of the profile school of arterial hypertension. Far East Medical Journal, 3, 13-15.

[12] Shemetova, G. N., Ryaboshapko, A. I., Gubanova, G. V. (2017). The role of schools for patients in secondary prevention of arterial hypertension. Saratov Journal of Medical Scientific Research, 13 (3), 481-483.

[13] Li, V. V., Kausova, G. K., Svitich, T. N., Karazhanova, L. K. (2014). Results of educational activity of school of health for patients with arterial hypertension - experience of 10 years of work. Science \& Health Care, 1, 31-34.

[14] Kontsevaya, A. V., Spivak, E. Yu., Kalinina A. M. (2011). Socio-economic effectiveness of Schools of Health for patients with IHD in primary health care. Effective pharmacotherapy. Cardiology and Angiology, 1, 92-97.

[15] Wood, D., Kotseva, K., Connolly, S., Jennings, C., Mead, A., Jones, J. et. al. (2008). Nurse-coordinated multidisciplinary, family-based cardiovascular disease prevention programme (EUROACTION) for patients with coronary heart disease and asymptomatic individuals at high risk of cardiovascular disease: a paired, cluster-randomised controlled trial. The Lancet, 371 (9629), 1999-2012. doi: http://doi.org/10.1016/ s0140-6736(08)60868-5

[16] Voogdt-Pruis, H. R., Beusmans, G. H., Gorgels, A. P., Kester, A. D., Van Ree, J. W. (2010). Effectiveness of nurse-delivered cardiovascular risk management in primary care: a randomised trial. British Journal of General Practice, 60 (570), 40-46. doi: http://doi.org/10.3399/bjgp10x482095

[17] Piepoli, M. F., Corrà, U., Adamopoulos, S., Benzer, W., Bjarnason-Wehrens, B., Cupples, M. et. al. (2012). Secondary prevention in the clinical management of patients with cardiovascular diseases. Core components, standards and outcome measures for referral and delivery. European Journal of Preventive Cardiology, 21 (6), 664-681. doi: http://doi.org/10.1177/2047487312449597

[18] Anderson, L., Taylor, R. S. (2014). Cardiac rehabilitation for people with heart disease: an overview of Cochrane systematic reviews. Cochrane Database of Systematic Reviews. doi: http:// doi.org/10.1002/14651858.cd011273.pub2

[19] Giannuzzi, P., Temporelli, P. L., Maggioni, A. P., Ceci, V., Chieffo, C. et. al. (2005). GlObal Secondary Prevention strategiEs to Limit event recurrence after myocardial infarction: the GOSPEL study. A trial from the Italian Cardiac Rehabilitation Network: rationale and design. European Journal of Cardiovascular Prevention \& Rehabilitation, 12 (6), 555-561. doi: http://doi.org/10.1097/01.hjr.0000186623.60486.26

[20] Giannuzzi, P., Temporelli, P. L., Marchioli, R., Maggioni, A. P., Balestroni, G., Ceci, V. et. al. (2008). Global secondary prevention strategies to limit event recurrence after myocardial infarction: results of the GOSPEL study, a multicenter, randomized controlled trial from the Italian Cardiac Rehabilitation Network. Archives of Internal Medicine, 168 (20), 2194. doi: http://doi.org/10.1001/archinte.168.20.2194 